\title{
Occupational mobility within and between skill clusters: an empirical analysis based on the skill-weights approach
}

\author{
Regula Geel *, Uschi Backes-Gellner \\ Department of Business Administration, University of Zurich
}

\begin{abstract}
This paper applies Lazear's skill-weights approach (2009) to analyze the specificity of skill combinations of various occupations and its effects on occupational mobility and wages. The results show that the more specific an occupation, the smaller the probability of an occupational change. We also identify clusters of occupations characterized by similar skill combinations and find that employees in specific occupations have a comparatively higher probability of changing occupations within a skill cluster than between skill clusters. Moreover, occupational mobility within a skill cluster results in wage gains, while between clusters it results in wage losses. Therefore, the acquired skill combination and the resulting skill cluster, rather than the occupation per se, crucially determines mobility. Thus, for educational policies, it is more important to study whether a skill cluster is sustainable than an occupation.
\end{abstract}

Keywords: Skill-weights approach, occupational mobility, apprenticeship
training

\section{Introduction}

Mobility and flexibility are increasingly demanded as structural change challenges established educational systems and traditional occupational demarcations. Due to continuous technological innovation, skill requirements not only increase rapidly but also change frequently (Autor et al., 2003; Autor \& Dorn, 2009). Educational systems must therefore provide graduates with both qualifications tailored to actual market needs and skills that are quickly adaptable to changing conditions and skill requirements (Winkelmann, 2006; Hotz-Hart, 2008; Spitz-Oener, 2008).

\footnotetext{
* Corresponding author: University of Zurich, Department of Business Administration, Plattenstrasse 14, CH-8032 Zurich.Email: regula.geel@ business.uzh.ch. This research is partly funded by the Swiss Federal Office for Professional Education and Technology through its Leading House on Economics of Education, Firm Behaviour and Training Policies. We thank the participants at the SASE in Paris, the TASKS-workshop in Nuremberg, the research seminars at the University of Zurich, and particularly Ed Lazear for helpful comments and suggestions. The data used in this paper from the «BIBB/ BAuA Employment Survey» were collected by the German Federal Institute for Vocational Education and Training (Bundesinstitut für Berufsbildung, BIBB) and the Federal Institute for Occupational Safety and Health (Bundesanstalt für Arbeitsschutz und Arbeitsmedizin, BAuA). The producers of the data do not bear any responsibility for the analysis and interpretation of the data in this paper.
} 
Although this structural change challenges all established educational systems, in particular, vocational education and training (VET) is often criticized as too inert and inflexible (Heckman, 1994; Carnoy, 2004; Krueger \& Kumar, 2004). In contrast to academic education, which is considered broad and general, VET is perceived as too focused on narrow skill requirements within one particular occupation.

In contrast, we argue that to appropriately evaluate different types of education, one must first and foremost analyze how the level of flexibility of vocational education can be measured and how the degree of this flexibility within vocational education is determined. In this paper, we argue that neither comparisons of academic education with vocational education nor the number of apprenticeship training occupations, the two common criteria to judge on flexibility, are relevant, but that we must rather consider the specificity of the acquired skill combination. We show that the skill combination, and not the occupation per se, crucially determines occupational mobility and the wage consequences of an employee.

Previous research on occupational mobility, however, focuses on occupational codes and occupations per $\mathrm{se}^{1}$ but does not engage in a detailed skill analysis. ${ }^{2}$ This omission is partly due to a lack of detailed skill data and partly to a lack of an analytical model that could guide a detailed empirical analysis of skills. Therefore, empirical research on skill-based mobility is still at an early stage. Nevertheless, in our paper, we are able to overcome both of these problems. On the one hand, we are able to work with a rich dataset that contains very detailed information on acquired and required skills as well as on educational and occupational careers. On the other hand, we build on Lazear's skill-weights approach (2009), which is ideal for studying occupational specificity at the level of single skills as well as the resulting bundles of these skills.

In applying a new, skill-oriented point of view, we are able to analyze occupational specificity and study the effects of acquired occupation-specific skill combinations on occupational mobility and income. We focus on the labor market segment in which an occupation with its skill bundle is embedded rather than on broad classification codes because occupations with similar skill combinations can be clustered into labor market segments (subsequently also referred to as skill clusters). This means that more relevant and more important than the occupation per se is the skill combination acquired and required in that occupation. Mobility has to be evaluated with respect to the entire labor market segment that is relevant for a skill combination and not only to the single occupation.

1 Occupational experience, which represents occupation-specific human capital, increases earnings (Kambourov \& Manovskii, 2009) and thus reduces occupational mobility (Shaw, 1987; Borghans \& Golsteyn, 2007; Kambourov \& Manovskii, 2008; Geel et al., 2009). However, employees also attempt to realize better income possibilities or career chances through occupational changes (Goeggel \& Zwick, 2009; Fitzenberger \& Spitz, 2004; Clark \& Fahr, 2001). Another strand of literature deals with job polarization (Autor et al., 2006; Dustman et al., 2009; Goos \& Manning, 2007); in contrast to these studies, we do not evaluate the skills in terms of being routine or non-routine, manual or cognitive, but we analyze mobility patterns based on particular skill combinations in occupations.

2 One exception is a recent paper by Poletaev and Robinson (2008) that analyzes mobility based on the skill portfolios of jobs and finds that wage losses are more closely associated with switching skill portfolios than switching occupation codes per se. 
Taken together, our study is innovative in at least three ways. First, we analyze occupational mobility at the level of single skills required in occupations as well as the resulting combinations of these skills. Second, we use Lazear's skill-weights approach (2009) as a theoretical framework that provides us with a new empirical approach to operationalize occupational specificity as well as to examine occupational mobility and that allows for a micro-founded analysis of specific and general human capital. Third, we determine occupational skill clusters containing occupations with similar skill combinations. We analyze the effects of the specificity of skill combinations on occupational mobility within and between these skill clusters and the impact of such occupational changes on income.

\section{Theoretical framework: The skill-weights approach (Lazear 2009)}

According to Lazear's model, all skills are general, but firms use them with different weights. Specificity, therefore, occurs because the required combination of skills varies from firm to firm. In the basic skill-weights model, there are only two skills and two periods. A worker invests in either skill in the first period at $\operatorname{cost} C(A, B)$ and receives a payoff in the second period according to the following earnings function:

$y_{i}=\lambda_{i} A+\left(1-\lambda_{i}\right) B$

$\lambda_{i}$ is the relative weight of skill A in firm i. Since $\lambda_{i}$ may be different from the relative weight of skill $A$ in any other firm $j$, the worker must determine the extent to which he wants to acquire skills $\mathrm{A}$ and $\mathrm{B}$. If the employee is certain that he will remain at the initial firm indefinitely, then he will focus on $\lambda_{i}$ and invest in the respective incomemaximizing skill bundle. However, if the employee cannot be certain that he will stay at the initial firm, he must consider looking for a new job in another firm. In case of a change, other firms may demand a different weighting of skills, rendering part of the employee's investment worthless and leading to a wage loss. The outside market determines how much his investment will depreciate depending on the difference between the weight of the initial firm and the expected market weight, $\lambda_{i}-\bar{\lambda}$. Thus, skill combinations can be rather general compared to the outside market (if the difference $\lambda_{i}-\bar{\lambda}$ is small, as is the expected wage loss) or rather specific (if the difference $\lambda_{i}-\bar{\lambda}$ is large, as is the expected wage loss). Thus, starting in an occupation with a specific bundle of skills strongly determines mobility and income for the rest of a worker's career.

\subsection{Application to apprenticeship training}

The advantage of using the skill-weights approach in our analysis is the theoretical foundation that allows us to study occupational specificity at the level of single skills and the resulting skill combinations. Thus, we use Lazear's basic idea and apply it to 
apprenticeship training in which the combination of acquired skills is given by the occupation of a graduate. ${ }^{3}$ We therefore use occupation-specific rather than firmspecific skill-weights. Because the expected lifetime net earnings are not only dependent on the skill-weights of the training occupation but also on the skill-weights outside in the total labor market, the individual investment problem involves choosing a training occupation and investing accordingly in its skills. Intuitively, employees in occupations with very specific skill combinations are faced with higher losses if they change their occupation because they will no longer be able to make use of all their skills. ${ }^{4}$

Furthermore, we consider different labor market segments. While Lazear's model regards the outside market as a whole as a relevant factor in occupational changes, we argue that in line with labor market segmentation theory (Doeringer \& Piore, 1971, for an overview see Leontardi, 1998) and occupational labor market theory (Marsden, 1986; Eyraud et al., 1990), the labor market is composed of a variety of segments, which may not all be equally relevant in the case of an occupational change. We expect the labor market to be segmented into different skill clusters. These skill clusters contain occupations with similar skill combinations within clusters but different skill combinations across clusters. Intuitively, even after an occupational change, an investment in a skill combination can still be valuable and productively used if the former and the new occupations are classified into the same skill cluster and require very similar skill combinations. The skill cluster with its average skill-weight $\bar{\lambda}_{k}$, thus represents the segment of the labor market that is relevant for potential occupational changes without a major loss in human capital investments. Therefore, the difference between the skill-weights of an individual occupation in comparison to the skill-weights of the respective skill segment $\lambda_{i}-\bar{\lambda}_{k}$ defines the cluster specificity of an occupation.

\subsection{Testable implications}

To test these implications, we differentiate two types of occupational specificity, namely, «total specificity», which compares the skill-weights of an occupation with the skill-weights across the total labor market, and «cluster specificity», which compares the skill-weights of an occupation with the skill-weights of the respective skill cluster. Furthermore, we define three types of occupational mobility: first, occupational mobility in total; second, occupational mobility within a skill cluster; and third, occupational mobility between skill clusters.

3 Lazear (2009: 932) briefly mentions this idea, suggesting that skill-weights are not only specific to firms, but rather that all individuals in an occupation have identical skill-weights. However, he does not provide empirical evidence for this particular application.

4 The cause of an occupational change is not important for our research question. We thus do not consider whether an occupational change was planed in the first place, but we rather analyze mobility patterns and their wage implications. 
According to Lazear, mobility is more likely if the skill-weights in one's actual employment are very similar to the skill-weights on the external labor market. Thus, regarding particular skill combinations, we expect the following patterns to occur:

\section{Probability of occupational mobility}

- H1: The more specific the skill combinations of occupations as compared to the total labor market, the smaller the likelihood that workers will change occupations after completion of apprenticeship training.

- H2: The more specific the skill combinations of occupations as compared to the total labor market, the greater the likelihood that workers who change occupations will change within a skill cluster rather than between skill clusters.

- H3: The more specific the skill combinations of occupations as compared to its respective skill cluster, the smaller the likelihood that workers will change occupations even within this skill cluster.

Furthermore, wage losses and wage gains may occur after occupational changes. If workers change occupations towards an occupation with a very similar skill combination, they lose little in terms of initial human capital investment and can use formerly acquired skills as productively as before. They may even gain by switching, for example, into an occupation with labor shortages and accordingly higher wages. Thus, for individuals who are mobile within clusters, wages may either remain constant or even increase. However, for changes between clusters, the skill combination will be very different from the original occupation. Thus, cluster changers lose severely in terms of their initial human capital investment because their skills may no longer be used as productively as before. The resulting loss may not be offset by wage gains due to a higher demand for the new occupation. This leads us to the following hypotheses:

\section{Income effects of occupational mobility}

- H4: a) Occupational changes between skill clusters cause wage losses. b) The size of the respective wage loss is expected to be the larger the more specific the skill combination of the occupation is as compared to the total labor market.

- H5: a) Occupational changes within skill clusters cause wage gains.

b) The size of the respective wage gain is expected to be the smaller the more specific the skill combination of the training occupation is within its relevant skill cluster. 


\section{Estimation methods}

\subsection{Probability of occupational mobility}

First, we study the impact of occupational specificity on the occupational mobility of employees. We differentiate not only so-called occupational stayers from occupational changers, but also occupational changers within from changers between skill clusters. We use the following probit model framework (Wooldridge, 2009: 575-578):

$$
\begin{aligned}
& y *_{o c}=\beta_{1} Z+\beta_{2} X+\varepsilon \\
& y_{o c}=1 \text { if } y *_{o c}>0 \\
& y_{o c}=0 \text { if } y *_{o c} \leq 0
\end{aligned}
$$

The latent index $y *_{o c}$ models the underlying process of a worker's decision to change occupation. In the case of occupational mobility, $y_{o c}$ takes the value one, and zero otherwise. $Z$ contains the main explanatory variable for specificity; therefore, $\beta_{1}$ is the influence of the specificity degree. $X$ contains the control variables, while $\varepsilon$ indicates the error term.

\subsection{Income effects of occupational mobility}

Second, we test the wage effects of occupational specificity and mobility on income by estimating a log-linear ordinary least square regression. The basic equation can be written as an extended Mincer (1974) earnings equation:

$\ln y=a+\beta_{1} M+\beta_{2} Z+\beta_{3}(Z * M)+\beta_{4} X+\varepsilon$

where $\ln y$ is $\log$ hourly earnings. $M$ contains the dummies for the two different types of occupational change (i.e. either within or between skill clusters); therefore, $\beta_{1}$ is the influence of an occupational change on earnings. $Z$ contains the main explanatory variable for specificity; therefore, $\beta_{2}$ is the influence of the specificity degree on earnings. $Z * M$ is an interaction term ${ }^{5}$ that we include to analyze the combined effect of specificity and mobility, $\beta_{3}$.X contains the control variables while $\varepsilon$ represents an unobservable error.

5 To reduce potential problems with multicollinearity due to interaction effects between a quantitative variable and a dummy variable in multiple regression analysis, we center the quantitative variable prior to the formation of the product term (Jaccard et al., 1990; Aiken \& West, 1991) so that a specificity degree of 0 corresponds to the mean specificity. 


\section{Data and variable construction}

Our empirical estimation is based on the BIBB/BAuA Employment Survey 2005/06, ${ }^{6}$ a representative cross-sectional sample of the working population in Germany. The dataset contains retrospective information on individual educational and occupational careers and - most importantly - the required skills at the workplace in detail, a crucial and unique feature of this dataset.

In our study, we focus on skilled workers with apprenticeship training and restrict our analysis to individuals between 18 and 65 years of age. Furthermore, we exclude all civil servants and all self-employed people. After eliminating observations with missing data, a sample of 4,217 male employees in 71 different occupations is included in the analysis. ${ }^{7}$ Table 1 reports the means and standard deviations of the variables used in our empirical analysis.

Table 1: Descriptions of variables

\begin{tabular}{lcccc}
\hline Variable & Mean & Std. dev. & Min. & Max. \\
\hline Occupational total specificity & 8.5 & 2.3 & 4.5 & 15.1 \\
Occupational cluster specificity & 3.7 & 2.3 & 1.2 & 10.8 \\
Occupational change & 0.58 & 0.49 & 0 & 1 \\
Occupational change within skill cluster & 0.21 & 0.41 & 0 & 1 \\
Occupational change between skill cluster & 0.37 & 0.48 & 0 & 1 \\
Hourly wage (ln) & 2.5 & 0.47 & 0.8 & 3.8 \\
Age & 40.2 & 9.8 & 18 & 65 \\
Married & 0.52 & 0.50 & 0 & 1 \\
Children & 0.45 & 0.50 & 0 & 1 \\
Blue collar & 0.35 & 0.48 & 0 & 1 \\
German nationality & 0.97 & 0.16 & 0 & 1 \\
East Germany & 0.15 & 0.35 & 0 & 1 \\
Tenure & 10.8 & 9.1 & 0 & 49 \\
Further training & 0.57 & 0.50 & 0 & 1 \\
Lower secondary school & 0.29 & 0.46 & 0 & 1 \\
Intermediate secondary school & 0.54 & 0.50 & 0 & 1 \\
High school diploma & 0.16 & 0.36 & 0 & 1 \\
No school graduation & 0.01 & 0.08 & 0 & 1 \\
Firm size under 10 employees & 0.20 & 0.40 & 0 & 1
\end{tabular}

6 BIBB/BAuA Employment Survey is a survey jointly conducted by the German Federal Institute for Vocational Education and Training (BIBB) and the Federal Institute for Occupational Safety and Health (BAuA).

7 We restrict our analysis to male employees to avoid difficulties related to the interrupted labor market histories of women. We furthermore lose some occupations that have too few observations per occupation to adequately represent the corresponding skill portfolio (occupations are grouped according to the (2-digit) classification of occupational titles by Germany's Federal Employment Bureau in 1992). 


\begin{tabular}{lllll} 
Firm size between 10 and 49 employees & 0.28 & 0.45 & 0 & 1 \\
Firm size between 50 and 249 employees & 0.23 & 0.42 & 0 & 1 \\
Firm size over 250 employees & 0.28 & 0.45 & 0 & 1 \\
Industry & 0.32 & 0.47 & 0 & 1 \\
Handcraft & 0.15 & 0.36 & 0 & 1 \\
Trade & 0.18 & 0.39 & 0 & 1 \\
Service & 0.34 & 0.47 & 0 & 1 \\
Other sector & 0.01 & 0.09 & 0 & 1 \\
\hline
\end{tabular}

Source: BIBB/BAuA 2005/2006, own calculations

\subsection{Dependent variables: Occupational mobility and income}

We use three different variables to measure occupational mobility, comparing the current occupations of workers at the time of the survey with their apprenticeship training occupations. First, we generate a variable representing an occupational change during an individual's working life, which stands for total occupational mobility. If workers no longer work in their original occupation, we consider this an occupational change, and the dependent variable takes the value of 1;0 otherwise. Overall, about $58 \%$ of employees in our sample changed their occupation, while about $42 \%$ did not.

Second, we generate a mobility variable covering only occupational changes occurring within a skill cluster (i.e. the labor market segment containing occupations with similar skill combinations), which represents mobility to an occupation with similar skill-weights. If an individual changed occupation and remained in the same skill cluster, the dummy variable takes the value 1; 0 otherwise.

Third, we generate a mobility variable covering only occupational changes occurring between skill clusters, representing mobility into an occupation with relatively different skill-weights. If the individual changed the occupation and the skill cluster, the dummy variable takes the value $1 ; 0$ otherwise.

Furthermore, the survey contains self-reported information on current monthly earnings and the average hours of work per week at the time of the survey; we were thus able to calculate individual hourly wages. ${ }^{8}$ In our estimates, the logarithm of wages is used as the dependent variable.

\subsection{Required skills and occupation-specific skill portfolios}

Based on the large set of questions about a worker's required skills, we are able to generate skill portfolios. The respondents were asked to report on skills that are required to perform their current job. If the respective skill is required at the workplace, the dummy variable takes the value of $1 ; 0$ otherwise. The left panel of Figure 1 , for example, shows the skill portfolio of an individual office clerk.

8 We do not include further monetary compensation, only the monthly earnings. Moreover, we dropped observations with earnings above the 99 th percentile or below the 1st percentile so that the results are not determined by outliers. 
Figure 1: Skill portfolio of office clerks: Individual and occupational level

Individual Office Clerk

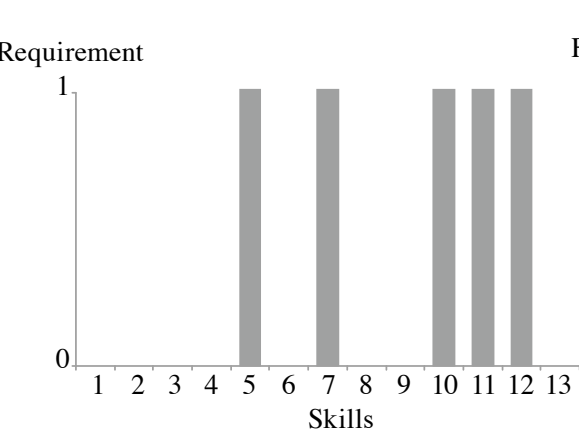

Expert Knowledge

Skills

1 Natural Science

2 Craft

3 Technical
4 Pedagogic

5 Law

6 Medical

Skill Portfolio Office Clerks

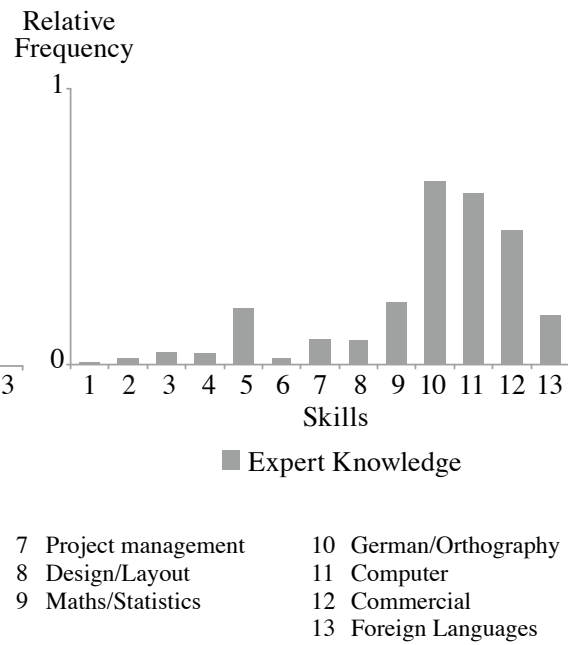

Source: BIBB/BAuA 2005/2006, own calculations

13 Foreign Languages

To determine the skill portfolio in an occupation, we aggregate the individual skill portfolios $^{9}$ of a particular occupation, leading to a weighted occupation-specific skill portfolio (see Figure 1, right panel). The occupational skill portfolio shows the relative frequency of the different skills required in that occupation. We build such occupational skill portfolios for all occupations in the sample. Thereby, we know the relative frequency of all skills in all occupations and are able to compare the different skill combinations.

\subsection{Skill clusters}

To determine how similar or dissimilar the skill combinations of different occupations are, we perform a cluster analysis including all occupations represented in the sample. Such a cluster analysis maximizes the homogeneity of skill combinations within clusters and maximizes heterogeneity between clusters; therefore, it is an ideal statistical method to identify the similarity or dissimilarity of occupational skill clusters (Mardia et al., 1979; Aldenderfer \& Blashfield, 1984; Bortz, 1989). We perform a cluster analysis using the 71 occupations as the units of analysis and the thirteen skills as the variables to define the clusters. We apply a two-stage procedure because research has shown that this approach increases the validity of solutions

9 To determine the skill portfolio of an occupation, we only look at workers who are still in the same occupation as during their apprenticeship training to ensure that we are indeed measuring the skills acquired and required for one particular occupation. 
(Punj \& Stewart, 1983; Ketchen \& Shook, 1996). We first use a hierarchical algorithm, i.e. Ward's (1963) minimum variance method, to define the number of clusters. This result serves as the starting point for the second stage of subsequent nonhierarchical clustering, i.e. the K-means procedure (Bortz, 1989).

As a result, we find six distinct skill clusters, ${ }^{10}$ each of which contains occupations with similar skill combinations. To summarize the characteristics of these clusters, Table 2 presents the relative importance of the single skills per skill cluster. For example, the most important skills in skill cluster 5, which contains the office clerk, are German orthography, computer and commercial skills. Thus, these cluster-specific skill combinations represent the average skill-weights of a labor market segment.

Table 2: The relative importance of single skills per skill cluster

\begin{tabular}{|c|c|c|c|c|c|c|c|}
\hline \multirow{2}{*}{\multicolumn{2}{|c|}{ Relative Importance }} & \multicolumn{6}{|c|}{ Clusters } \\
\hline & & (1) & $(2)$ & (3) & (4) & $(5)$ & (6) \\
\hline \multirow[t]{13}{*}{ Skills } & Natural Science & 0.35 & 0.22 & 0.15 & 0.29 & 0.06 & 0.18 \\
\hline & Craft & 0.41 & 0.83 & 0.75 & 0.40 & 0.04 & 0.14 \\
\hline & Technical & 0.58 & 0.72 & 0.33 & 0.63 & 0.16 & 0.14 \\
\hline & Pedagogic & 0.04 & 0.10 & 0.07 & 0.12 & 0.16 & 0.35 \\
\hline & Law & 0.11 & 0.11 & 0.07 & 0.15 & 0.37 & 0.19 \\
\hline & Medical & 0.00 & 0.05 & 0.03 & 0.03 & 0.05 & 0.34 \\
\hline & Project management & 0.03 & 0.08 & 0.05 & 0.16 & 0.18 & 0.10 \\
\hline & Design/Layout & 0.03 & 0.06 & 0.08 & 0.31 & 0.15 & 0.08 \\
\hline & Maths/Statistics & 0.24 & 0.50 & 0.22 & 0.52 & 0.27 & 0.14 \\
\hline & German/Orthography & 0.16 & 0.20 & 0.10 & 0.29 & 0.62 & 0.39 \\
\hline & Computer & 0.06 & 0.17 & 0.04 & 0.48 & 0.55 & 0.09 \\
\hline & Commercial & 0.17 & 0.06 & 0.09 & 0.03 & 0.39 & 0.19 \\
\hline & Foreign Languages & 0.03 & 0.06 & 0.07 & 0.22 & 0.28 & 0.09 \\
\hline
\end{tabular}

Source: BIBB/BAuA 2005/2006, own calculations

10 We determine a candidate number of six clusters by examining the results of the first stage (visual inspection of the dendrogram that gives the distances between observations within clusters and distances between clusters (Wagschal, 1999; Ketchen \& Shook, 1996) and use of Mardia et al.'s (1979: $365)$ rule of thumb, $\mathrm{g} \sim(\mathrm{n} / 2)^{1 / 2}$ for the number of groups) and refine the clusters in the following second stage. Note that our research follows Osberg et al. (1987), who applied six labor market segments and is along the line of the six broad occupational groups according to the one-digit classification codes of occupational titles by Germany's Federal Employment Bureau in 1992. The cluster analysis fulfils the robustness check according to Wagschal's F-Test (1999: 272); 80\% of the calculated F-values do not exceed the value of one, which means that the variance within the clusters is smaller than the total variance. 


\subsection{Explanatory variables: Cluster specificity and total specificity}

Knowing the relative frequencies of single skills per occupation and per skill cluster, we are able to quantify the specificity of skill combinations and generate our two explanatory variables. We use an index to measure the degree of specificity of occupations according to the skill-weights approach. Comparing the importance of single skills in an occupation with the relevant skill cluster (see Figure 2, left panel), we are able to derive the cluster specificity of a particular occupation. As expected, the skill portfolios of occupations in the same skill cluster show very similar frequencies of required skills.

Figure 2: Comparison of an occupation-specific skill portfolio with the skill portfolio of the relevant skill cluster

Comparison of Skill Portfolios

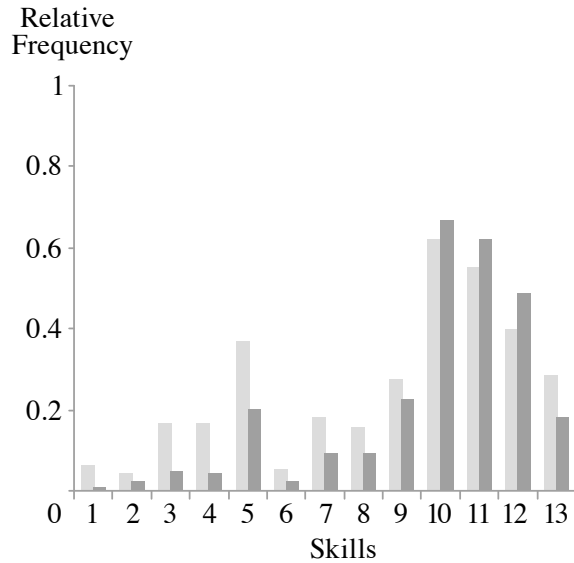

Skill Cluster 5 Office Clerk
Ranks and absolute Rank-Differences of Skills

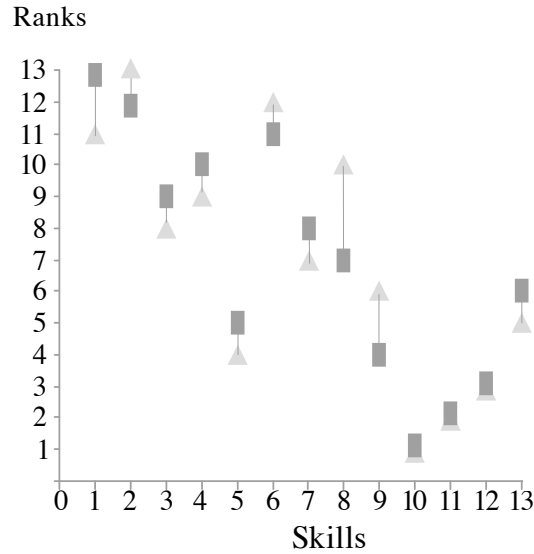

Skill Cluster $5 \quad$ Office Clerk

Skills

$\begin{array}{llll}1 & \text { Natural Science } & 4 & \text { Pedagogic } \\ 2 & \text { Craft } & 5 & \text { Law } \\ 3 & \text { Technical } & 6 & \text { Medical }\end{array}$

Source: BIBB/BAuA 2005/2006, own calculations

\author{
7 Project management \\ 8 Design/Layout \\ 10 German/Orthography \\ 9 Maths/Statistics \\ Computer \\ 12 Commercial \\ 13 Foreign Languages
}

We therefore rank the skills of each occupation and each skill cluster according to their relative frequencies. For each occupation, we calculate the distances between the ranks of single skills in the occupation portfolio and the respective skill cluster. An example of how these distances look is given in the right panel of Figure 2. Next, we weight these absolute rank-differences of all single skills with the corresponding relative frequency of the respective skill cluster and sum them. The larger this number is, the more atypical are the skills needed for a particular occupation even 
within its skill cluster. Thus, a large number indicates that the skill-weights in the occupation are quite different from the skill-weights in its respective labor market segment. Therefore, the resulting variable provides us with a degree of specificity according to the skill-weights approach.

The total specificity is generated in the same manner, but the occupation-specific skill combination is compared to the total labor market of all apprenticeship graduates in our sample; that is, to the average skill combination of all occupations rather than to its respective skill cluster. Geel, Mure and Backes-Gellner (forthcoming) describe the operationalization of the specificity index in greater detail.

\section{Empirical results}

\subsection{Probability of occupational mobility}

We now discuss the key results concerning occupational specificity and mobility (Table 3). In model 1, we analyze occupational mobility in total across the entire labor market and find a negative impact of occupational total specificity as expected according to hypothesis H1. To exemplify, an increase of a training occupation's total specificity of a standard deviation relative to those occupations with average specificity in the whole labor market results in a decrease in the probability of an occupational change of $4.8 \%$. This means the more specific the apprenticeship training occupation as compared to the whole labor market, the lower occupational mobility after graduation (in line with Shaw, 1987; Borghans \& Golsteyn, 2007).

Table 3: Probability of occupational mobility (probit model)

\begin{tabular}{lcc}
\hline & Specification & \\
\hline Model 1: & Model 2: & Model 3:
\end{tabular}

\begin{tabular}{|c|c|c|c|c|c|c|c|c|c|}
\hline $\begin{array}{l}\text { Dependent } \\
\text { variable }\end{array}$ & \multicolumn{3}{|c|}{$\begin{array}{c}\text { Occupational change } \\
\text { in total }\end{array}$} & \multicolumn{3}{|c|}{$\begin{array}{l}\text { Occupational change } \\
\text { within skill clusters }\end{array}$} & \multicolumn{3}{|c|}{$\begin{array}{l}\text { Occupational change } \\
\text { within skill clusters }\end{array}$} \\
\hline $\begin{array}{l}\text { Reference } \\
\text { category }\end{array}$ & \multicolumn{3}{|c|}{ Occupational stayers } & \multicolumn{3}{|c|}{$\begin{array}{l}\text { Occupational changers } \\
\text { between clusters }\end{array}$} & \multicolumn{3}{|c|}{ Occupational stayers } \\
\hline \multirow[t]{2}{*}{ Focus } & \multicolumn{3}{|c|}{ Overall labor market } & \multicolumn{3}{|c|}{ Overall labor market } & \multicolumn{3}{|c|}{ Labor market segment } \\
\hline & $\mathrm{dF} / \mathrm{dx}$ & Std. erro & & $\mathrm{dF} / \mathrm{dx}$ & Std. error & & $\mathrm{dF} / \mathrm{dx}$ & Std. error & \\
\hline $\begin{array}{l}\text { Occupational total } \\
\text { specificity }\end{array}$ & -0.024 & 0.004 & $* * *$ & 0.086 & 0.006 & $* * *$ & & & \\
\hline $\begin{array}{l}\text { Occupational } \\
\text { cluster specificity }\end{array}$ & & & & & & & -0.032 & 0.006 & $* * *$ \\
\hline Age & 0.033 & 0.006 & $* * *$ & -0.015 & 0.008 & $* *$ & 0.017 & 0.008 & $* *$ \\
\hline Age squared & 0.000 & 0.000 & $* * *$ & 0.000 & 0.000 & $*$ & 0.000 & 0.000 & \\
\hline Married & -0.001 & 0.020 & & -0.018 & 0.024 & & -0.030 & 0.025 & \\
\hline Children & 0.002 & 0.020 & & 0.021 & 0.024 & & 0.013 & 0.025 & \\
\hline Further training & -0.010 & 0.016 & & -0.036 & 0.020 & $*$ & -0.029 & 0.020 & \\
\hline East Germany & 0.026 & 0.023 & & 0.006 & 0.028 & & -0.006 & 0.030 & \\
\hline
\end{tabular}




\begin{tabular}{|c|c|c|c|c|c|c|c|c|c|}
\hline $\begin{array}{l}\text { Firm size } \leq 9 \\
\text { employees }\end{array}$ & -0.072 & 0.028 & $* *$ & 0.031 & 0.034 & & -0.043 & 0.033 & \\
\hline $\begin{array}{l}\text { Firm size } 10 \text { to } 49 \\
\text { employees }\end{array}$ & -0.081 & 0.023 & $* * *$ & -0.054 & 0.025 & $* *$ & -0.105 & 0.026 & $* * *$ \\
\hline $\begin{array}{l}\text { Firm size } 50 \text { to } \\
249 \text { employees }\end{array}$ & -0.054 & 0.022 & $* *$ & -0.003 & 0.024 & & -0.053 & 0.025 & $* *$ \\
\hline \multicolumn{10}{|c|}{ Reference category: Services } \\
\hline Industry & 0.003 & 0.022 & & 0.096 & 0.024 & $* * *$ & 0.019 & 0.028 & \\
\hline Handcraft & -0.277 & 0.026 & $* * *$ & 0.166 & 0.039 & $* * *$ & -0.194 & 0.027 & $* * *$ \\
\hline Trade & 0.064 & 0.026 & $* *$ & -0.050 & 0.029 & & 0.036 & 0.037 & \\
\hline Other sector & -0.221 & 0.072 & $* * *$ & -0.104 & 0.095 & & -0.246 & 0.044 & $* * *$ \\
\hline \multicolumn{10}{|c|}{ Reference category: Intermediate secondary school } \\
\hline $\begin{array}{l}\text { No school } \\
\text { graduation }\end{array}$ & -0.036 & 0.100 & & 0.262 & 0.123 & $* *$ & 0.056 & 0.119 & \\
\hline $\begin{array}{l}\text { Lower secondary } \\
\text { school }\end{array}$ & -0.035 & 0.018 & $*$ & 0.060 & 0.022 & $* * *$ & -0.025 & 0.023 & \\
\hline $\begin{array}{l}\text { High school } \\
\text { diploma }\end{array}$ & 0.098 & 0.022 & $* * *$ & 0.022 & 0.026 & & 0.164 & 0.033 & $* * *$ \\
\hline $\begin{array}{l}\text { Number of } \\
\text { observations }\end{array}$ & $4^{\prime} 217$ & & & $2^{\prime} 590$ & & & $2^{\prime} 417$ & & \\
\hline Wald chi ${ }^{2}(17)$ & 443.22 & & & 280.88 & & & 239.37 & & \\
\hline Prob $>$ chi $^{2}$ & 0.00 & & & 0.00 & & & 0.00 & & \\
\hline Pseudo $\mathrm{R}^{2}$ & 0.08 & & & 0.10 & & & 0.08 & & \\
\hline
\end{tabular}

Notes: Robust standard errors; all coefficients represent marginal effects. * Statistically significant at the .10 level; ** at the .05 level; *** at the .01 level

In the next step, we are interested in differences in mobility patterns. To test hypothesis $\mathrm{H} 2$, we apply our labor market segmentation and only look at occupational changers to compare occupational mobility within and between skill clusters (model 2 ). In line with our hypothesis, we find that the higher the occupational total specificity, the more likely are occupational changes into occupations with relatively similar skill requirements (i.e. within a skill cluster) than changes into occupations with relatively dissimilar skill requirements (i.e. between skill clusters). An increase in total specificity of a standard deviation results in an increase in the probability of an occupational change within a skill cluster of $18.1 \%$ as compared to an occupational change between skill clusters. Therefore, although an occupation is very specific, a graduate is nonetheless able to change occupation after graduation into an occupation with similar skills within a labor market segment.

According to hypothesis $\mathrm{H} 3$, we finally analyze individual mobility behavior within a skill cluster (model 3 ). Although occupations grouped in a skill cluster have similar skill requirements, they nonetheless differ in specificity, as we have shown in the operationalization of the specificity degree. As expected, we find that even within a skill cluster, individuals with more cluster-specific occupations are less likely to 
change their occupations within their labor market segment. An increase in cluster specificity of a standard deviation results in a decrease in the probability of an occupational change within a skill cluster of $5.9 \% .^{11}$

\subsection{Income effects of occupational mobility}

We now discuss the key results concerning the income effects of occupational specificity and mobility (Table 4). In model 4 , we test our fourth hypothesis and analyze occupational changes between skill clusters. In accordance with hypothesis $\mathrm{H} 4 \mathrm{a}$, we find a negative impact of an occupational change between skill clusters on income. An occupational change between skill clusters is associated with a 5\% reduction in hourly wages as compared to the wages of stayers (in line with the finding of Poletaev and Robinson, 2008, that switching skill portfolios generates wage losses; however, we further expect income gains if occupational changes occur within skill clusters). The coefficient of occupational total specificity is statistically insignificant, but the interaction term between total specificity and an occupational change between skill clusters - that shows the combined effect of specificity and mobility - is statistically significant and negative as expected according to hypothesis $\mathrm{H} 4 \mathrm{~b}$. Thus, in the case of an occupational change between skill clusters, the more specific the skill portfolio in an occupation relative to the total labor market, the higher the wage loss that a cluster changer has to bear. Therefore, employees who change their skill clusters suffer a wage loss that increases with the specificity of the skill requirements of the former occupation.

Table 4: Income effects of occupational mobility (OLS regression)

\begin{tabular}{|c|c|c|c|c|c|}
\hline \multirow{4}{*}{$\begin{array}{l}\text { Dependent variable: } \\
\text { Hourly wage (ln) }\end{array}$} & \multirow{2}{*}{\multicolumn{5}{|c|}{ Specification }} \\
\hline & & & & & \\
\hline & \multirow{2}{*}{\multicolumn{2}{|c|}{$\begin{array}{l}\text { Model 4: } \\
\text { Occupational change } \\
\text { between } \text { skill clusters }\end{array}$}} & \multicolumn{3}{|c|}{ Model 5: } \\
\hline & & & \multicolumn{3}{|c|}{$\begin{array}{c}\text { Occupational change } \\
\text { within skill clusters }\end{array}$} \\
\hline Reference category & \multicolumn{2}{|c|}{ Occupational stayers } & \multicolumn{3}{|c|}{ Occupational stayers } \\
\hline \multirow[t]{2}{*}{ Focus } & \multicolumn{2}{|c|}{ Overall labor market } & & \multicolumn{2}{|c|}{ Labor market segment } \\
\hline & Coefficient & $\begin{array}{l}\text { Std. } \\
\text { error }\end{array}$ & & Coefficient & $\begin{array}{l}\text { Std. } \\
\text { error }\end{array}$ \\
\hline $\begin{array}{l}\text { Occupational change between } \\
\text { skill clusters }\end{array}$ & -0.050 & 0.015 & $* * *$ & & \\
\hline Occupational total specificity & 0.005 & 0.005 & & & \\
\hline Interaction term & -0.012 & 0.007 & $*$ & & \\
\hline $\begin{array}{l}\text { Occupational change within } \\
\text { skill cluster }\end{array}$ & & & & 0.068 & $0.017 * * *$ \\
\hline Occupational cluster specificity & & & & -0.010 & $0.004 * *$ \\
\hline
\end{tabular}

11 As a robustness check, we compute the regressions with occupational clusters to consistently estimate the standard errors and also obtain significant results; in models 1 and 3 , the specificity effects were significant at the $10 \%$ level, and in model 2 at the $1 \%$ level. 


\begin{tabular}{|c|c|c|c|c|c|c|}
\hline Interaction term & & & & 0.002 & 0.009 & \\
\hline Age & 0.035 & 0.005 & $* * *$ & 0.030 & 0.006 & $* * *$ \\
\hline Age squared & 0.000 & 0.000 & $* * *$ & 0.000 & 0.000 & $* * *$ \\
\hline Married & 0.054 & 0.015 & $* * *$ & 0.036 & 0.017 & $* *$ \\
\hline Children & 0.012 & 0.015 & & 0.025 & 0.017 & \\
\hline Tenure & 0.021 & 0.002 & $* * *$ & 0.018 & 0.002 & $* * *$ \\
\hline Tenure squared & 0.000 & 0.000 & $* * *$ & 0.000 & 0.000 & $* * *$ \\
\hline German nationality & 0.059 & 0.036 & & 0.015 & 0.034 & \\
\hline Blue collar & -0.173 & 0.014 & $* * *$ & -0.132 & 0.016 & $* * *$ \\
\hline East Germany & -0.285 & 0.019 & $* * *$ & -0.297 & 0.021 & $* * *$ \\
\hline Further training & 0.101 & 0.012 & $* * *$ & 0.059 & 0.013 & $* * *$ \\
\hline Reference category: Firm size $\geq$ & loyees & & & & & \\
\hline Firm size $\leq 9$ employees & -0.225 & 0.024 & $* * *$ & -0.201 & 0.024 & $* * *$ \\
\hline Firm size 10 to 49 employees & -0.159 & 0.016 & $* * *$ & -0.142 & 0.018 & $* * *$ \\
\hline Firm size 50 to 249 employees & -0.091 & 0.015 & $* * *$ & -0.082 & 0.018 & $* * *$ \\
\hline Reference category: Services & & & & & & \\
\hline Industry & 0.181 & 0.018 & $* * *$ & 0.052 & 0.021 & $* *$ \\
\hline Handcraft & 0.077 & 0.021 & $* * *$ & -0.049 & 0.023 & $* *$ \\
\hline Trade & -0.024 & 0.022 & & -0.098 & 0.025 & $* * *$ \\
\hline Other sector & 0.009 & 0.057 & & -0.122 & 0.057 & $* *$ \\
\hline Reference category: Intermedia & ary schoo & & & & & \\
\hline No school graduation & 0.011 & 0.068 & & -0.064 & 0.064 & \\
\hline Lower secondary school & -0.052 & 0.013 & $* * *$ & -0.056 & 0.015 & $* * *$ \\
\hline High school diploma & 0.097 & 0.020 & $* * *$ & 0.088 & 0.022 & $* * *$ \\
\hline Constant & 1.701 & 0.104 & $* * *$ & 1.911 & 0.110 & $* * *$ \\
\hline $\mathrm{n}$ & & 3427 & & & 2417 & \\
\hline F-Statistics & & 108.11 & & & 73.31 & \\
\hline Prob $>$ F & & 0.00 & & & 0.00 & \\
\hline R-Squared & & 0.40 & & & 0.38 & \\
\hline
\end{tabular}

Notes: Robust standard errors. *Statistically significant at the .10 level; **at the .05 level; ***at the .01 level

In the last step, we test our fifth hypothesis that focuses on labor market segments, and we analyze occupational changes within a skill cluster (model 5). As expected according to our hypothesis H5a, occupational changes within skill clusters have a significantly positive effect on income. An occupational change within a skill cluster is associated with a $6.8 \%$ increase in income relative to occupational stayers (similar to the realization of better income possibilities through occupational changes shown 
by Fitzenberger and Spitz (2004); however, their analysis neglects underlying skills). In line with hypothesis H5b, occupational cluster specificity has a negative and significant effect on income, while the coefficient of the interaction term is statistically insignificant. Therefore, an occupational change within a skill cluster is honored with a wage gain. However, the more specific the skill portfolio of the former occupation relative to the respective skill cluster, the smaller this wage gain.

\section{Conclusions}

Our analysis of occupational mobility shows that although vocational education and training (VET) is often criticized as too inert and inflexible and too focused on narrow skill requirements, VET does not severely restrict mobility but provides graduates with different types of flexibility. We find clear evidence supporting our theoretical predictions, and thus, occupational specificity can be analyzed according to Lazear's skill-weights approach (2009): particular skill combinations have implications on mobility and income. Our paper contributes to the literature in analyzing occupational mobility on the skill-level and providing a novel definition of specificity. Therefore, the acquired skill combination - and not the occupation per se - crucially determines the mobility of an employee.

Several conclusions can be drawn about the specificity of occupational skill combinations and their implications for occupational mobility and income. First, there is evidence of distinct segments within the labor market (in line with labor market segmentation theory); skill clusters exist that contain occupations with similar skillweights or skill combinations. These skill clusters are important in an analysis of occupational mobility after apprenticeship training.

Second, the required skill combination is a good measure of the flexibility of occupations and determines the degree of specificity of an occupation. The more specific an occupation is, the smaller the probability that employees will change their occupation not only across the total labor market but also within their skill cluster. Nonetheless, even employees in specific occupations can be mobile, as they have a comparatively higher probability of changing occupations within a skill cluster rather than between skill clusters. Therefore, within skill clusters, flexibility is facilitated, whereas between skill clusters, flexibility is constrained. Thus, the mobility of graduates of a particular apprenticeship training occupation can still be high even if the occupation is very small and does not offer many job opportunities as long as there are other occupations within the same skill cluster into which they can change without a substantial loss of human capital.

Third, an occupational change within skill clusters is possible without losing formerly acquired skills and, moreover, is honored with a wage gain. Since the required skill combination is quite similar, the return on the formerly acquired skills is not lost. However, occupational mobility into occupations with very different skill combinations, e.g. occupational mobility between skill clusters, is associated with a wage loss because the returns on formerly acquired skills are partially lost. Not sur- 
prisingly, the higher the degree of specificity of the former occupation, either the higher the resulting wage loss or the smaller the resulting wage gain depending on whether the change is between or within skill clusters, respectively. However, although occupational changes between skill clusters are associated with a wage loss, empirically, many employees change occupations between clusters. Obviously, occupational mobility is not only motivated by increased pay. We assume that these changes are, for example, related to health, family issues or general changes in one's personal situation.

Our findings lead to several implications for research and educational policy. In a comparison of VET versus academic training, appropriate measures must be used to determine the relative competitiveness of programs. Therefore, previous conclusions must be reviewed. Regarding educational policy, it is important to look not only at a single occupation when thinking about future competitiveness and mobility issues but also at the skill cluster within which a particular occupation is located because the cluster is as important for mobility and earnings as the occupation itself. Therefore, choosing a seemingly outdated and very specific occupation could be a better decision, if it is in a prosperous cluster, than choosing a seemingly general occupation that lies is in a very small and less prosperous cluster.

Moreover, we find that the relevant parameter to evaluate the flexibility of an occupational system and the employability of its graduates is the specificity of the skill combination in comparison to similar occupations within the skill cluster and in comparison to the total labor market. Based on Lazear's skill-weights approach, we argue that the specificity of the skill combination in an occupation is the relevant issue to be analyzed, and these skill combinations can be quite similar, even though a multitude of occupations exist.

\section{References}

Aiken, L. S. \& West, S. G. (1991). Multiple regression: Testing and interpreting interactions. Newbury Park: SAGE

Aldenderfer, M. S. \& Blashfield, R. K. (1984). Cluster analysis. SAGE University papers on quantitative applications in the social sciences, No. 07-044. Beverly Hills: SAGE

Autor, D. H.; Levy, F. \& Murnane, R. J. (2003). The skill content of recent technological change: An empirical exploration. Quarterly Journal of Economics, 118(4), 1279-1333

Autor, D. H.; Katz, L. F. \& Kearney, M. S. (2006). The polarization of the U.S. labor market. The American Economic Review, 96(2), 189-194

Autor, D. \& Dorn, D. (2009). This job is «getting old»: Measuring changes in job opportunities using occupational age structure. American Economic Review, 99(2), 45-51

Borghans, L. \& Golsteyn, B. H. H. (2007). Skill transferability, regret and mobility. Applied Economics, 39(13), 1663-1677

Bortz, J. (1989). Statistik für Sozialwissenschaftler. Berlin/Heidelberg/New York: Springer

Carnoy, M. (2004). Education for all and the quality of education: a reanalysis. Background paper prepared for the Education for all global monitoring report 2005, The Quality Imperative

Clark, D. \& Fahr, R. (2001). The promise of workplace training for non-college-bound youth: Theory and evidence from German apprenticeship. IZA Discussion Paper, No. 378. Bonn: IZA

Doeringer, P. B. \& Piore, M. J. (1971). Internal labor markets and manpower analysis. Lexington, Mass.: Heath 
Dustmann, C.; Ludsteck, J. \& Schönberg, U. (2009). Revisiting the German wage structure. The Quarterly Journal of Economics, 124, 843-881

Eyraud, F.; Marsden, D. \& Silvestre, J. (1990). Occupational and internal labour markets in Britain and France. International Labour Review, 129(4), 501

Fitzenberger, B. \& Spitz, A. (2004). Die Anatomie des Berufswechsels: eine empirische Bestandsaufnahme auf Basis der BIBB/IAB-Daten 1998/1999. ZEW Discussion Paper No. 04-05. Mannheim: Zentrum für Europäische Wirtschaftsforschung

Geel, R.; Mure, J. \& Backes-Gellner, U. (forthcoming). Specificity of occupational training and occupational mobility: An empirical study based on Lazear's skill-weights approach. Education Economics

Geel, R.; Mure, J. \& Backes-Gellner, U. (2009). Berufliche Bildung und Mobilität: Erklärungen mit Hilfe des Skill-weights Approach. Empirische Pädagaogik, 23, 479-498

Goeggel, K. \& Zwick, T. (2009). Good occupation - Bad occupation? The quality of apprenticeship training. ZEW Discussion Paper No. 09-024. Mannheim: Zentrum für Europäische Wirtschaftsforschung

Goos, M. \& Manning, A. (2007). Lousy and lovely jobs: the rising polarization of work in Britain. The Review of Economics and Statistics, 89(1), 118-133

Heckman, J. J. (1994). Is job training oversold? The Public Interest, 115, 91-115

Hotz-Hart, B. (2008). Erfolgskonzept «duale Berufsbildung» im Wandel, In: T. Bauder \& F. Osterwalder (Eds.): 75 Jahre eidgenössisches Berufsbildungsgesetz. Politische, pädagogische, ökonomische Perspektiven. Bern: hep

Jaccard, J.; Wan, C. K. \& Turrisi, R. (1990). The detection and interpretation of interaction effects between continuous variables in multiple regression. Multivariate Behavioral Research, 25(4), 467-478

Kambourov, G. \& Manovskii, I. (2008). Rising occupational and industry mobility in the United States: 1968-97. International Economic Review, 49(1), 41-79

Kambourov, G. \& Manovskii, I. (2009). Occupational specificity of human capital. International Economic Review, 50(1), 63-115

Ketchen, D. J. \& Shook, C. L. (1996). The application of cluster analysis in strategic management research: An analysis and critique. Strategic Management Journal, 17(6), 441-458

Krueger, D \& Kumar, K. B. (2004). Skill-specific rather than general education: A reason for US-Europe growth differences? Journal of Economic Growth, 9(2), 167-207

Lazear, E. P. (2009). Firm-specific human capital: A skill-weights approach. Journal of Political Economy, 117(5), 914-939

Leontardi, M. R. (1998). Segmented labour markets: Theory and evidence. Journal of Economic Surveys, 12(1), 63-101

Mardia, K. V.; Kent, J. T. \& Bibby, J. M. (1979). Multivariate analysis. London: Academic Press.

Marsden, D. (1986). The end of economic man? custom and competition in labour markets. Brighton: Wheatsheaf Books

Mincer, J. (1974). Schooling, experience, and earnings. New York: National Bureau of Economic Research

Osberg, L.; Apostle, R. \& Clairmont, D. (1987). Segmented labour markets and the estimation of wage functions. Applied Economics, 19(12), 1603-1624

Poletaev, M. \& Robinson, C. (2008). Human capital specificity: Evidence from the dictionary of occupational titles and displaced worker surveys, 1984-2000. Journal of Labor Economics, 26(3), 387-420

Punj, G., Stewart, D. W. (1983). Cluster analysis in marketing research: Review and suggestions for application. Journal of Marketing Research, 20(2), 134-148

Shaw, K. L. (1987). Occupational change, employer change, and the transferability of skills. Southern Economic Journal, 53(3), 702-719

Spitz-Oener, A. (2008). The returns to pencil use revisited. Industrial and Labor Relations Review, 61(4), 502-517

Wagschal, U. (1999). Statistik für Politikwissenschaftler. München/Wien: Oldenbourg

Ward, J. H. (1963). Hierarchical grouping to optimize an objective function. Journal of the American Statistical Association, 58(301), 236-244

Winkelmann, R. (2006). Qualifikationsspezifische Beschäftigungsperspektiven und berufliche Flexibilität, In: A. Frick \& A. Wirz (Eds.) Berufsbildungsökonomie: Stand und offene Fragen. Bern: hep

Wooldrige, J. (2009). Introductory econometrics: A modern approach. South-Western Cengage Learning 